\title{
THE APPLICATION RESEARCH OF MOBILE ROBOTS WITH FORKLIFT-DRIVING-WHEELS CAPABLE TO ASCEND AND DESCEND STAIRS
}

\author{
Hirofumi NIIMI \\ College of Industrial Technology \\ Department of Systems Design \\ 1-27-1 nishikoya amagasaki city hyogo prefecture JAPAN \\ niimi@cit.sangitan.ac.jp
}

\author{
Noriyoshi DOUHARA \\ College of Industrial Technology \\ Department of Mechanical Engineering \\ 1-27-1 nishikoya amagasaki city hyogo prefecture JAPAN \\ dohara@cit.sangitan.ac.jp
}

\begin{abstract}
To ascend and descend stairs, we have developed the robot assembling fork lifts on the front and the rear. Those fork lifts have driving wheels. The FDW robot (mobile robot with Forklift-Driving-Wheels capable to ascend and descend stairs) is divided into three parts (Body, Front Forklift-Wheels, Rear Forklift-Wheels). The robot can move up and down by the front and rear fork lifts, and also it can be transferred by using these through the stairs and the step. If a condition is satisfied, the robot can get up from the turnover condition by using the fork lifts. The size of a robot being able to go up the stairs of 1-step height $200 \mathrm{~mm}$ width $300 \mathrm{~mm}$ becomes about $300 \times 300 \times 300 \mathrm{~mm}$. When a fork lift is set at 2-step-type, the miniature robot of the height $150 \mathrm{~mm}$ can be made. If the entire length of the robot is more than $300 \mathrm{~mm}$, the robot can go up the stairs by assembling the Sub-Rear Fork-lift Wheels. The application such as the wheelchair which can go up the stairs is expected. The position of the chair is lowered in the form that a human being turns a back to the stairs as much as possible to go up the stairs safely. A FDW robot can be applied to a cleaning robot, a guidance robot, a robot for the education and a robot for the baggage conveyance, a wheelchair to go up the stairs, and so on.
\end{abstract}

Keywords: Mobile Robot, Forklift-Wheel, Stairs, Wheelchair.

\section{INTRODUCTION}

A wheel-type mobile robot, when it moves through the level ground, is better than a leg-type mobile robot in the point of the cost and the energy. But that robot can't go up the step and the stairs. If the wheel-type mobile robot can go up the stairs and the step, the robot can moves to various places where a human being lives at the daily life. The development of the wheel-type mobile robot which goes up the stairs and the step is expected.

A robot goes up the stairs with a different structure by the relations of the relative size of the stairs and the robot. When a robot is small in comparison with the size of the stairs, stairs are a cliff and a high wall for the robot. In this case, a robot must go up the stairs by the jump, the flight and the wall side movement. When a robot is big in comparison with the stairs, it doesn't care about the step with crawler and so on, and it can go up. When size is the middle, a robot must go up the stairs each one step.
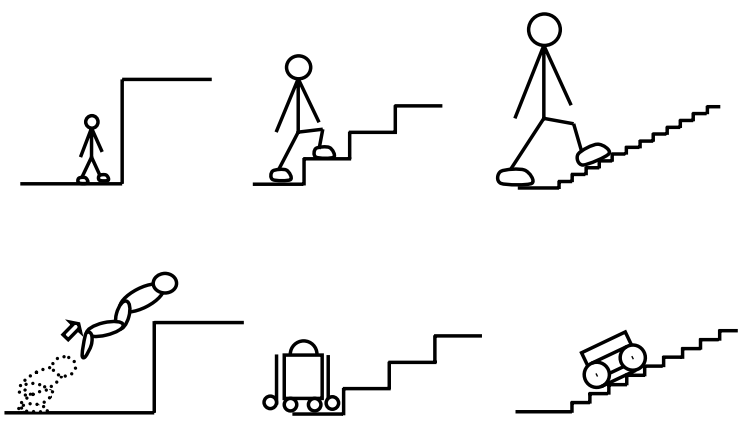

Fig. 1 Relative size with robot and stairs.
To make a robot in the middle size go up stairs, we have developed the robot assembling fork lifts on the front and the rear [1]. A robot from $100 \mathrm{~mm}$ to about $1 \mathrm{~m}$ can be made by using this structure. If a condition is satisfied, a robot can get up from the tipping condition by using a fork lift. It explains about the robot of the miniature, the medium size and the large size, and moreover it is examined about a wheelchair to go up the stairs.

\section{THE FDW ROBOT}

The mobile robot with Forklift-Wheels capable to ascend and descend stairs is shown in figure 2. The FDW robot (mobile robot with Forklift-Driving-Wheels capable to ascend and descend stairs) is divided into three parts (Body, Front Forklift-Wheels, Rear Forklift-Wheels). Those fork lifts have driving wheels. The robot can move up and down by the front and rear fork lifts, and also it can be transferred by using these through the stairs and the step.

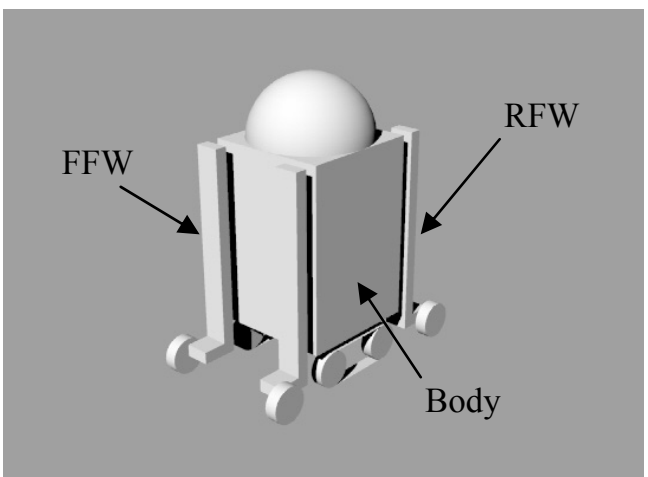

Fig. 2 Mobil robot with Forklift-Wheels. 


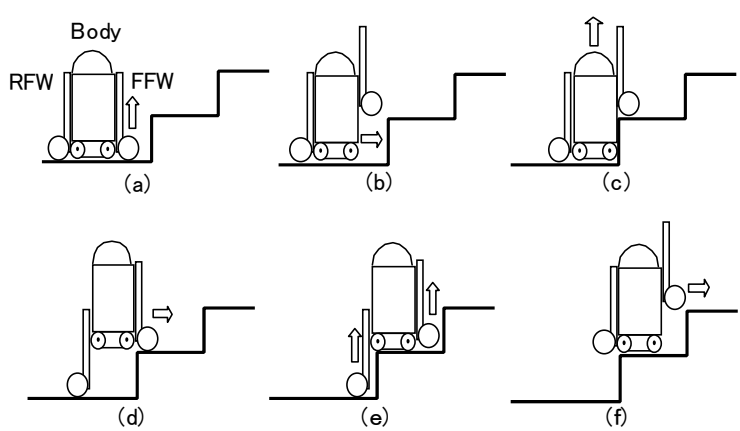

Fig. 3 Moving patterns on stairs.
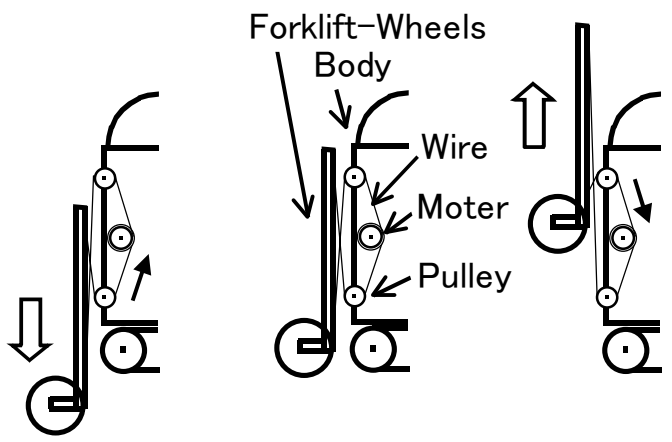

Fig. 4 Mechanism of Forklift-Wheels slide system.
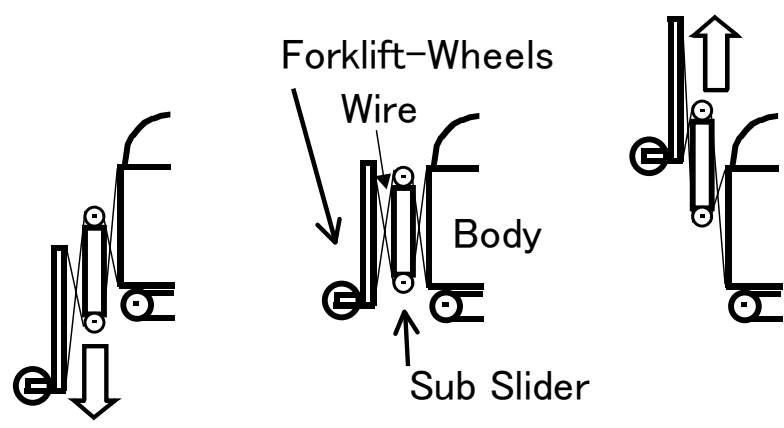

Fig. 5 Mechanism of two-tier Forklift-Wheels slide system.

The process that robot goes up the stairs is shown in figure 3, and it explains in the following. (a) FFW is raised in the high state of the step. (b) A robot is made to go, and made to touch stairs. (c) Body is supported with FFW and RFW, and it is raised. (d) A robot moves forward with wheels of FFW and RFW. (e) It raises RFW. And, it raises FFW as a preparation to go up the next step at the same time. (f) A robot became the same condition as (b). A robot goes up the stairs by repeating a series of movements. A robot can go up the stairs by the series of above processes. A robot can come down the stairs by doing up a reverse movement from (f) to (e) (d) (c) (b) (a).

The mechanism which moves a fork lift is shown in figure 4 . Though a fork works only upward in the case of a general fork lift, a fork can be moved downward by fixing a wire on top and bottom symmetrically. A wire is reeled with a motor, and a fork lift is moved up and down. A robot can be moved by using this mechanism through the stairs from both the front and the back.

The mechanism of two-step-type fork lift is shown in figure 5. A mechanism is divided into three parts of the fork lift part, the sub-slide part and the body. A fork lift part and a body are united with two wires. One wire is fixed in the bottom part of the fork lift part, and it passes at the top of the sub-slide, and fixed in the bottom part of the body. The second wire is fixed symmetrically in top and bottom. A fork lift part moves up and down when it moves a sub-slide up and down. A sub-slide is moved with a mechanism of figure 4 . A robot can be moved by using this mechanism through the high step. A FDW robot can be applied to a cleaning robot, a guidance robot, a robot for the education and a robot for the baggage conveyance, a wheelchair to go up the stairs, and so on.

\section{RETURN FROM THE TIPPING CONDITION}

A robot falls by some causes. It explains about the case that a robot fell backward as is shown in the figure 6. When a fork lift under body is raised, body moves, and becomes (b). When a fork lift is raised more, a robot rotates around the wheel of the bottom side, and becomes the condition of (c). Next, body gets up when a fork lift is lowered. A robot gets up smoothly when the fork lift of the upside is extended like (d) at this time.

Two mechanisms are thought as a fork lift part. The first is the mechanism which has front and back two fork lifts as is shown in the figure 7 (A). The second is the mechanism which has four fork lifts which were independent as figure 7 (B) in the right and left. Ten motors are necessary for the case of $(B)$. The $(A)$ has the advantage that the number of motors can be reduced. A robot can be moved as is shown in the figure (C) through the slope in the case of (B).

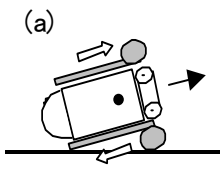

(d)

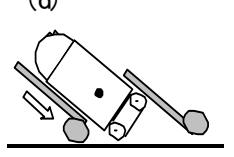

(b)

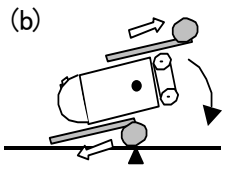

(e)

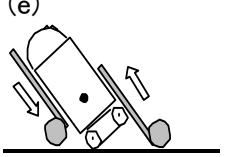

(c)

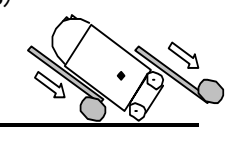

(f)

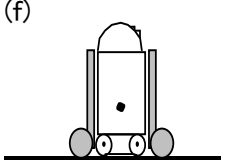

Fig.6 Sitting up patterns in the case of falling down backward.

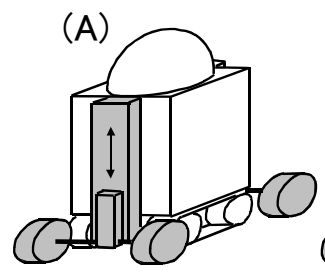

(B)

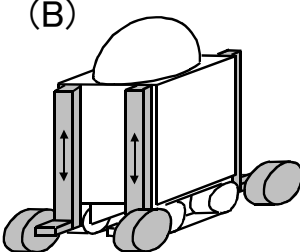

(C)

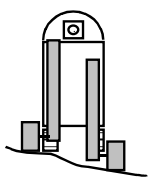

Fig. 72 Forklift-Wheels and 4 Forklift-Wheels. 
(A)

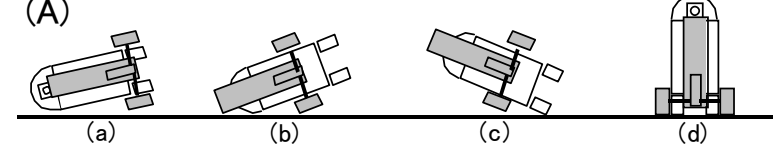

(B)

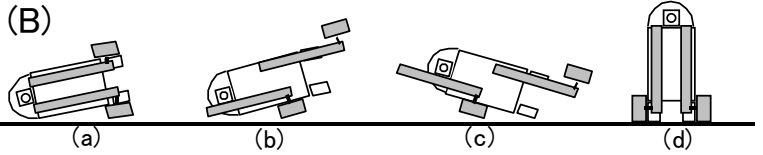

Fig. 8 Sitting up patterns in the case of falling down sideward.

When it falls at the side, it can get up as well as the time when it fell in the front or the back. The fork lift of front and back is raised as shown in the figure 8 (A) first. When it becomes a condition as shown in the figure 8 (c), a robot can get up by lowering a fork lift. The robot which has four fork lifts can get up smoothly when it shifts from the condition (c) of shown in the figure 8 (B) to the condition (d).

\section{The DESIGN CONDITION}

4.1 The design condition for stairs going up and down

The condition for a robot to go up and down the stairs is as the following.

4.1.1 The condition for the height of the stairs

FFW must be raised higher than one-step height of the stairs as shown in figure 9 (a).

$$
\mathrm{H} \leq \mathrm{S}_{\mathrm{F}}
$$

$\mathrm{H}$ shows the height of the stairs, and an $\mathrm{S}_{\mathrm{F}}$ shows the amount of movement of FFW.

RFW must descend as shown in figure 9 (b) lower than one-step height of the stairs.

$$
\mathrm{H} \leq \mathrm{S}_{\mathrm{R}}
$$

$\mathrm{H}$ shows the height of the stairs, and $\mathrm{S}_{\mathrm{R}}$ shows the amount of movement of RFW.

(a)

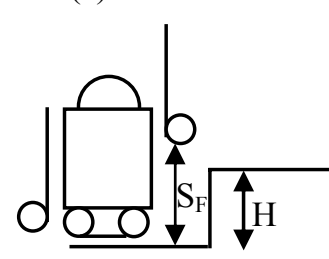

Fig. 9 Necessary condition of the slide length of FFW and RFW to hight of a step to go up the stairs. (a)

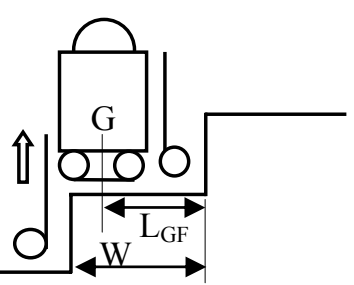

(b)

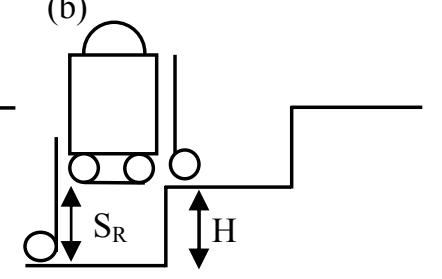

Fig. 10 Necessary condition to width of a step to go up the stairs.

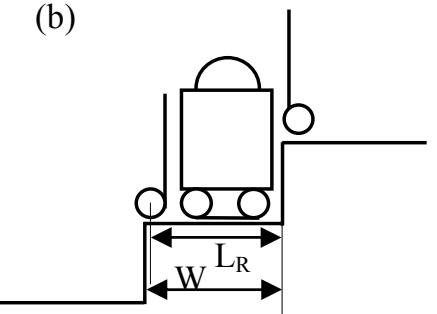

4.1.2 The condition for the width of the stairs

It is necessary that the center of gravity is as shown in figure 10 (a) on the step which crawler touches at the time of the rise in RFW.

$$
\mathrm{L}_{\mathrm{GF}}<\mathrm{W}
$$

$\mathrm{W}$ shows the width of the stairs, and $\mathrm{L}_{\mathrm{GF}}$ shows a distance from the center of gravity of the robot to the front of FFW.

It is necessary for RFW to be on the step which crawler touches as shown in figure 10 (b) at the time of the rise in body.

$$
\mathrm{L}_{\mathrm{RB}}<\mathrm{W}
$$

$\mathrm{W}$ shows the width of the stairs, and $\mathrm{L}_{\mathrm{RB}}$ shows a distance from the center of the tire of RFW to the front of body.

4.2 The design condition for return from the tipping condition

A position in the center of gravity is important when it shifts from the figure 8 (c) to (d). A robot falls in the left when the center of gravity is high as shown in the figure $11(\mathrm{~A}) \mathrm{g}$. It is necessary that the center of gravity G always exists in the right more than A to get up. It takes about the case that the radius of the wheel of body is equal to the wheel of the fork lift part for the simplification. Length $\mathrm{a}, \mathrm{b}, \mathrm{c}$ and the position of the fork lift are shown in the figure 11. The relations of the length of $\alpha, \beta$ and $\gamma$ must fill with the following equation so that the center of gravity $\mathrm{G}$ may come to the right more than A.

$$
\alpha>\gamma-\beta
$$

Because three right-angled triangles are similar, the next relation can be reduced.

$$
a^{2}+x^{2}>x c-a b
$$

The next equation can be obtained as a condition that $\mathrm{x}$ fills a relation (6).

$$
c^{2}-4\left(a^{2}+a b\right)<0
$$

Relations between a and $\mathrm{c}$ are shown in figure 11 in the case of $b=1$

When a robot is designed, it is necessary to make the length of $\mathrm{c}$ come to the bottom more than the curve shown in the figure 11 (D). It becomes $c<2 \sqrt{2}(c<2.8)$ in case of $a=1$ and $b=1$. A robot can get up even if the center of gravity isn't made too much low.
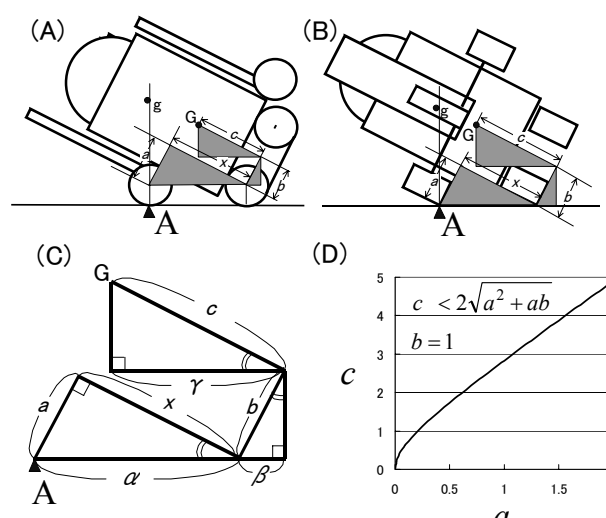

(D)

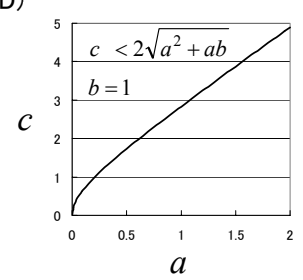

Fig. 11 Design planning for the robot to sit up. 


\section{THE DEVELOPMENT OF THE PROTOTYPE}

The prototype robot of the fork lift wheel going up and down stairs was made. The experiment of stairs going up and down and the experiment of the return from the turnover condition were done. The robot of one-step-type fork lift and the robot of two-step-type fork lift were developed. A fork lift-wheel became unstable on the skid of the stairs. Therefore, when the robot of two-step-type fork lift was developed, the improvement was done from the wheel to crawler as shown figure 12. The robot of 1-step-type fork lift can go up the step of $200 \mathrm{~mm}$. The robot of 2-step-type fork lift can go up the step of $320 \mathrm{~mm}$ though it is a miniature more than the robot of 1-step-type fork lift. Stairs going up and down was tested, and it was confirmed that it could go up the stairs. Next, the experiment of the return from the turnover was done (figure 13). It was confirmed that it could get up smoothly.

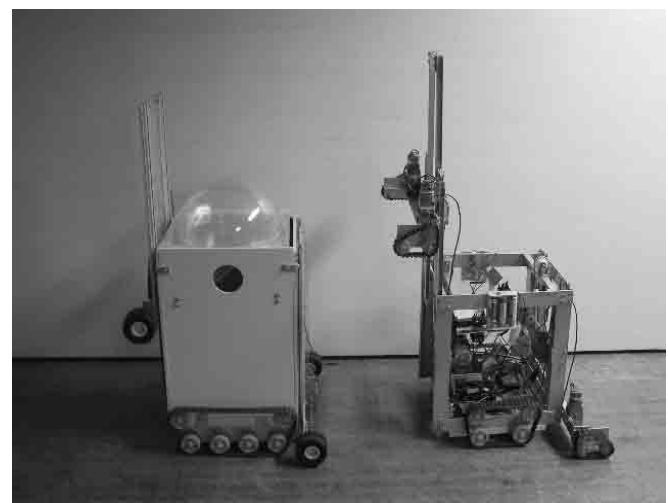

Fig. 12 Mobil robot with Forklift-Wheels.
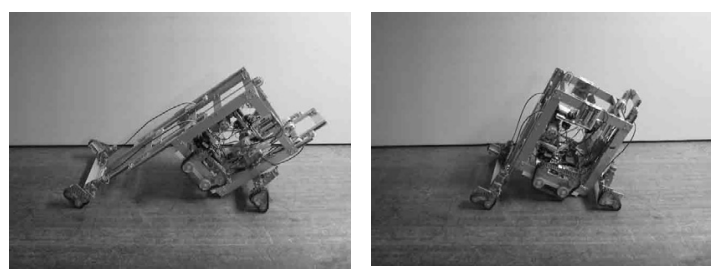

Fig. 13 Sitting up patterns in the case of falling down.

\section{THE LARGE SIZE ROBOT AND WHEELCHAIR}

An idea is necessary in the case of a robot of the large size which is not within width of the stairs. A large robot can go up the stairs by assembling Sub Rear Forklift-Wheel (SRFW) at the back on the side of body. The process that it goes up the stairs is shown in figure 14. A robot goes up the stairs using RFW and SRW alternately in the fundamentally similar process.

The application such as the wheelchair which can go up the stairs is expected. The position of the chair had better be low to go up the stairs safely. The way of going up the stairs in the back is proposed to realize that. The process which a wheelchair goes up from the stairs is shown in figure 15. Sliders are assembled before and behind the wheelchair. The wheel which has three wheels is assembled for the slider.

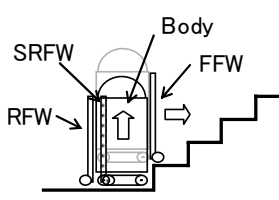

(a)

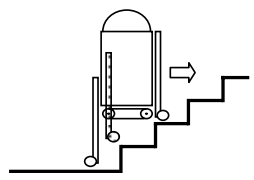

(d)

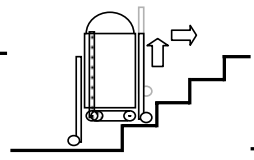

(b)

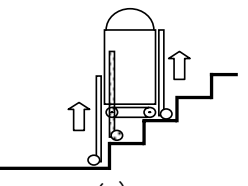

(e)

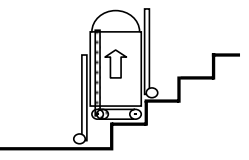

(c)

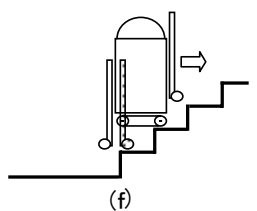

Fig. 14 Moving patterns on stairs in the case of large size robot.

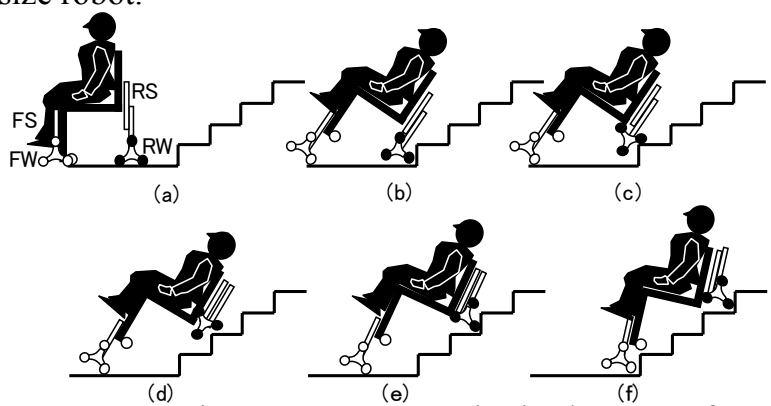

Fig. 15 Moving patterns on stairs in the case of wheelchair.
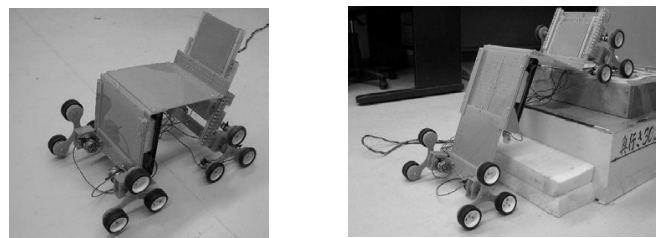

Fig. 16 The prototype of wheelchair of the size $1 / 2$.

The wheelchair can be slanted by using the slider. A wheelchair goes up the stairs by using the wheel which has three wheels.

The wheelchair of the size $1 / 2$ was manufactured as an experiment to verify theory. The photograph of the wheelchair is shown in figure 16. The stairs (height $100 \mathrm{~mm}$ and the size $150 \mathrm{~mm}$ of the step) of $1 / 2$ of the standard size were made, and it was confirmed that it could go up the stairs. And, when a wheelchair moved forward, it could get over the step of $60 \mathrm{~mm}$.

\section{SUMMARY}

The robot which put a fork lift before and behind the body was developed to go up the stairs. It was explained about the robot of the miniature, the medium size and the large size, and moreover it was examined about the wheelchair which went up the stairs.

\section{REFERENCES}

[1] Hirofumi NIIMI, Noriyoshi DOUHARA , "Development of Mobile Robot With Forklift-Wheel Mechanism Capable Step over Stairs." BULLETIN OF COLLEGE OF INDUSTRIAL TECHNOLOGY, pp121-pp126,vol.33(1999) 